\title{
PENGEMBANGAN SOAL MATEMATIKA MODEL PISA PADA MATERI TRANSFORMASI GEOMETRI KELAS XI
}

\author{
${ }^{1}$ Nurul Mardhiyah, ${ }^{2}$ Nouri Alfin Nabilah, ${ }^{3}$ Khoirul Ibad Al A'rif Billah, ${ }^{4}$ Wardatul \\ Jannah, ${ }^{5}$ Dimas Danar Septiadi \\ 1,2,3,4,5 Program Studi Tadris Matematika Institut Agama Islam Negeri Jember \\ Jalan Mataram No.1, Karang Miuwo, Mangli, Kec. Kaliwates, Kab. Jember, Jawa Timur 68136 \\ Email : ${ }^{1}$ nurulmardhiyah@gmail.com
}

\begin{abstract}
Abstrak
Penelitian ini bertujuan untuk menghasilkan soal matematika model PISA pada materi transformasi geometri untuk siswa kelas XI. Metode penelitian yang digunakan adalah research and development study. Analisis data adalah analisis deskriptif. Hasil penelitian berupa seperangkat soal matematika model PISA pada materi transformasi geometri yang sebanyak 8 butir soal. Valid dari segi konten, konstruk, dan bahasa berdasarkan penilaian validator. Soal-soal ini juga memberikan stimulus kepada siswa untuk berpikir kritis menggunakan penalaran sendiri dalam penyelesaiannya. Aspek penting dalam pengembangan soal PISA ini adalah pemahaman konsep transformasi geometri dan kemampuan menggunakan angka untuk mewakili atribut kuantitatif objek dunia nyata. Soal disusun sesuai kerangka kerja (framework) PISA dan diadaptasikan dengan kurikulum K13 revisi pada kelas XI KD 3.5 tentang menganalisis dan membandingkan transformasi dan komposisi transformasi dengan menggunakan matriks dan KD 4.5 Menyelesaikan masalah yang berkaitan dengan matriks transformasi geometri (translasi, refleksi, dilatasi, dan rotasi). Dari uji validasi didapatkan bahwa keseluruhan soal valid dengan rincian nilai validitas 2.8 untuk soal nomor 1 dan 2, nilai 3.3 untuk soal nomor 3 dan 4, nilai 2.9 untuk soal nomor 5 dan 6 , serta nilai 2.4 untuk soal nomor 7 dan 8 .
\end{abstract}

Kata Kunci: PISA, Research and Development Study, Trasformasi Geometri.

\begin{abstract}
This study aims to produce a math problem of the PISA model on geometry transformation for class XI students of high school. The research method used is Research and Development Study. Data analysis is descriptive analysis. The results of the study in the form of a set of mathematical models of PISA model on geometry transformation of 8 points. Valid in terms of content, construct, and language based on validator assessment. These questions also provide stimulus to students to think critically using their own reasoning in its solution. An important aspect of the development of this PISA is an understanding of the concept of geometry transformation and the ability to use numbers to represent the quantitative attributes of real world objects. The question was prepared according to the Framework of the PISA and was adapted to the K13 revised curriculum in the class XI with KD 3.5 about analyzing and comparing transformation and transformation composition by using the matrix and KD 4.5 resolving problems related to the matrix on geometry transformation.
\end{abstract}

\section{PENDAHULUAN}

Matematika sebagai salah satu mata pelajaran yang diajarkan di sekolah tentu memiliki peran dalam mencapai tujuan pendidikan yang diamanahkan undang-undang. Tujuan pendidikan matematika yaitu agar peserta didik memiliki kemampuan: (1) memahami konsep matematika, menjelaskan keterkaitan antarkonsep dan mengaplikasikan konsep atau algoritma secara luwes, akurat, efisien, dan tepat, dalam pemecahan masalah; (2) menggunakan penalaran pada pola dan sifat, melakukan manipulasi matematika dalam membuat 
generalisasi, menyusun bukti, atau menjelaskan gagasan dan pernyataan matematika; (3) memecahkan masalah yang meliputi kemampuan memahami masalah, merancang model matematika, menyelesaikan model dan menafsirkan solusi yang diperoleh; (4) mengkomunikasikan gagasan dengan simbol, tabel, diagram, atau media lain untuk memperjelas keadaan atau masalah; (5) memiliki sikap menghargai kegunaan matematika dalam kehidupan, yaitu memiliki rasa ingin tahu, perhatian, dan minat dalam mempelajari matematika, serta sikap ulet dan percaya diri dalam pemecahan masalah (Pulungan: 2014)

Tujuan pembelajaran matematika yang ditetapkan Departemen Pendidian Nasional sejalan dengan NCTM (2000: 67) yang menetapkan lima kompetensi dalam pembelajaran matematika: pemecahan masalah matematis (mathematical problem solving), komunikasi matematis (mathematical communication), penalaran matematis (mathematical reasoning), koneksi matematis (mathematical connection), dan representasi matematis (mathematical representation). Gabungan kelima kompetensi tersebut perlu dimiliki siswa agar dapat mempergunakan ilmu matematika dalam kehidupan sehari-hari. Kemampuan yang mencakup kelima kompetensi tersebut adalah kemampuan literasi matematika.

PISA (Program for International Student Assessment) merupakan sebuah penilaian secara internasional yang diselenggarakan oleh OECD terhadap keterampilan dan kemampuan siswa usia 15 tahun. Keterampilan dan kemampuan dalam PISA yang dinilai meliputi matematika, membaca, dan sains. Fokus dari PISA adalah literasi yang menekankan pada keterampilan dan kompetensi siswa yang diperoleh dari sekolah agar dapat digunakan dalam kehidupan sehari-hari (Johar:2012). PISA pertama dilaksanakan pada tahun 2000 dan kemudian dilaksanakan 3 tahun sekali.

Negara Indonesia telah beberapa kali mengikuti survei ini. Walaupun demikian, hasil PISA matematika Indonesia masih tergolong rendah. Hal ini terlihat dari peringkat yang dicapai Indonesia. Hasil studi PISA 2015 menunjukkan Indonesia baru bisa menduduki peringkat 69 dari 76 negara. Survei ini dilakukan oleh OECD (Organisation for Economic Co-operation and Development). Analisis yang digunakan oleh OECD berdasarkan pada hasil tes matematika dan ilmu pengetahuan. Peningkatan terbesar terlihat pada kompetensi sains, dari 382 poin pada tahun 2012 menjadi 403 poin di tahun 2015. Dalam kompetensi matematika meningkat dari 375 poin di tahun 2012 menjadi 386 poin di tahun 2015 . Kompetensi membaca mengalami peningkatan dari 396 di tahun 2012 menjadi 397 poin di tahun 2015 (Fathani: 2016). 
Rendahnya prestasi siswa Indonesia dalam PISA matematika dapat dipengaruhi oleh berbagai hal. Salah satu hal yang dapat dilakukan untuk mengatasinya adalah dengan membiasakan siswa berlatih soal-soal model PISA. Pembiasaan ini dapat dimulai dari pembelajaran di kelas. Oleh karena itu, perlu dikembangkan soal-soal setara PISA dengan konteks Indonesia baik oleh guru, peneliti, ataupun mahasiswa yang sedang menyelesaikan tugas akhir. Salah satu cara membantu guru untuk melaksanakan pembelajaran berbasis soal PISA, dengan tujuan membiasakan siswa adalah dengan menyediakan bank soal model PISA (Kohar: 2014).

Belajar menggunakan konteks menjadikan siswa menemukan hubungan bermakna antara ide-ide abstrak dan aplikasi praktis dalam konteks dunia nyata. Selain itu, penggunaan konteks lokal dapat membantu siswa memahami fenomena matematika dari perspektif pengalaman hidup mereka sendiri. Hal ini menjadikan matematika jauh lebih menarik dan bermanfaat bagi semua siswa. Berkaitan dengan hal ini, hasil penelitian di Hong Kong mendapati bahwa item-item dalam PISA sering digunakan dalam studi penelitian tes pencapaian matematika. Namun demikian, sangat disayangkan pengembangan item tes berbasis konteks dalam kearifan lokal masih kurang. Berkaitan dengan hal ini, soal-soal kontekstual yang lebih terkait dengan kehidupan sehari-hari siswa di tempat tinggal mereka sangat menarik untuk mengaktifkan siswa dalam pembelajaran. Soal-soal seperti ini juga akan menantang proses berpikir matematis siswa (Kadir: 2013).

PISA mempunyai kerangka kerja (framework) yang didasarkan pada tiga komponen, yaitu: isi atau konten matematika; proses yang perlu dilakukan peserta didik ketika mengamati suatu gejala, menghubungkan gejala itu dengan matematika, kemudian memecahkan masalah yang diamatinya (Fathani:2016). Berdasarkan framework PISA matematika 2015, konten matematika dalam PISA terdiri dari perubahan dan hubungan, ruang dan bentuk, bilangan, serta ketidakpastian dan data. Bermacam-macam konten yang lebih spesifik di dalamnya, seperti geometri, pola bilangan, aljabar, serta probabilitas dan ketidakpastian dan data. Soal-soal literasi pada studi PISA menuntut kemampuan penalaran dan pemecahan masalah yang menekankan pada berbagai masalah dan situasi dalam kehidupan sehari- hari Kemampuan yang diujikan dalam PISA dikelompokkan dalam komponen proses, yaitu kemampuan pemahaman dan pemecahan masalah (problem solving), kemampuan penalaran (reasoning), dan kemampuan komunikasi (communication).

Beberapa penelitian tentang pengembangan soal PISA yang telah dilakukan di antaranya berjudul Pengembangan Soal Matematika Model PISA Menggunakan Konteks 
Jambi yang ditulis oleh Ninik Charmila, Zulkardi, Darmawijoyo. Kemampuan Berpikir Tingkat Tinggi Siswa SMP di Kabupaten Jember dalam Menyelesaikan Soal Berstandar PISA yang ditulis oleh Dian Kurniati, Romi Harimukti, Nur Asiyah Jamil. Selain itu, terdapat pula Pengembangan Instrumen Tes Literasi Matematika MODEL PISA yang ditulis oleh Delyanti Azzumarito Pulungan, selanjutnya Ambarsari Kusuma Wardani juga menulis jurnal yang berjudul Pengembangan Soal Matematika Model PISA untuk Program Pengayaan Kelas VII SMP. Hal ini menunjukkan bahwa banyak pihak tertarik dan menganggap pengembangan soal model PISA sangat perlu dilakukan. Meski demikian, belum ada yang mengembangkan soal PISA pada materi transformasi geometri untuk siswa kelas XI SMA.

Di dalam kehidupan sehari-hari, seringkali kita menjumpai peristiwa atau kegiatan yang berhubungan dengan Ilmu Matematika. Salah satunya "Transformasi Geometri” yang memuat translasi, refleksi, rotasi, dan dilatasi. Dimana translasi adalah transformasi yang memindahkan setiap titik pada bidang dengan jarak dan arah tertentu. Refleksi adalah pencerminan, yaitu proses mencerminkan setiap titik bangun geometri itu terhadap garis tertentu (sumbu cermin/sumbu simetri). Rotasi adalah transformasi dengan cara memutar objek dengan titik pusat tertentu. Dilatasi adalah transformasi yang mengubah ukuran bangun tetapi tidak mengubah bentuknya.

Dari uraian tersebut, maka peneliti tertarik melakukan penelitian dengan judul "Pengembangan Soal Matematika Model PISA pada Materi Transformasi Geometri Kelas XI SMA".

\section{METODE PENELITIAN}

Penelitian ini menggunakan research and development study. Metode penelitian ini digunakan untuk menghasilkan produk tertentu, dan menguji keefektifan produk tersebut. Produk tersebut tidak selalu berbentuk benda atau perangkat keras (hardware), seperti buku, alat tulis, dan alat pembelajaran lainnya. Akan tetapi, dapat pula dalam bentuk perangkat lunak (software) (Sugiyono: 2007).

Tahapan pengembangan soal terdiri dari tahap persiapan (preliminary) dan tahap prototyping (formative evaluation) (Zulkardi: 2002). Pada tahap preliminary, peneliti melakukan analisis kurikulum untuk kelas XI SMA KD 3.5 tentang menganalisis dan membandingkan transformasi dan komposisi transformasi dengan menggunakan matriks dan KD 4.5 Menyelesaikan masalah yang berkaitan dengan matriks transformasi geometri (translasi, refleksi, dilatasi, dan rotasi) serta analisis soal-soal PISA. Kemudian peneliti 
mendesain perangkat soal meliputi kisi-kisi soal dan butir soal matematika model PISA pada materi transformasi geometri. Perangkat yang dihasilkan pada tahap ini dinamakan prototype awal. Kemudian pada prototype awal ini dilakukan tahap formative evaluation (Charmila: 2016 ; Putra: 2016).

Tahap pertama yang dilakukan pada formative evaluation ini adalah self evaluation. Perangkat soal yang telah dibuat dievaluasi sendiri oleh peneliti. Dalam hal ini penulis mendapat bantuan dari beberapa orang teman sejawat yang telah berpengalaman dalam pengembangan soal-soal PISA. Hasil dari self evaluation ini disebut prototype. Langkah selanjutnya yang dilakukan terhadap prototype adalah prototyping. Tahap ini dilakukan dengan expert reviews. Tahap expert reviews merupakan pengujian validitas butir soal oleh pakar (expert). Hal ini dilakukan dengan cara mencermati dan menilai setiap butir soal berdasarkan konten, konstruk, dan bahasa. Konten yang dinilai adalah kesesuaian dengan kurikulum yang digunakan dan materi yang dipelajari siswa tingkat SMA. Konstruk yang dicermati adalah kesesuaian dengan karakteristik soal PISA. Validasi bahasa yang dimaksud adalah kesesuaian penggunaan bahasa pada butir soal dengan kaidah bahasa yang berlaku (EYD). Saran dan komentar yang disampaikan oleh validator dijadikan sebagai masukan untuk revisi prototype. Temuan yang diperoleh pada tahap expert reviews digunakan dalam merevisi prototype.

Instrumen yang digunakan dalam penelitian ini berupa lembar validasi yang digunakan pada saat proses validasi oleh para ahli.

\section{HASIL DAN PEMBAHASAN(Heading 1)}

\section{Tahap Preliminary}

Pada tahap ini peneliti melakukan analisis kurikulum untuk kelas XI SMA KD 3.5 tentang Menganalisis dan membandingkan transformasi dan komposisi transformasi dengan menggunakan matriks dan KD 4.5 Menyelesaikan masalah yang berkaitan dengan matriks transformasi geometri (translasi, refleksi, dilatasi, dan rotasi) serta analisis soal- soal PISA. Kemudian peneliti mendesain perangkat soal meliputi kisikisi soal dan butir soal matematika model PISA pada materi transformasi geometri. Perangkat yang dihasilkan pada tahap ini dinamakan prototype awal. Berikut adalah prototype awal sebelum divalidasi oleh ahli dapat dilihat pada Gambar 1, 2, 3, 4, 5, 6, 7, 8. 
Bima dan Wahyu sedang bermain catur. Posisi pion mereka jika digambarkan pada bidang koordinat kartesius adalah seperti berikut.

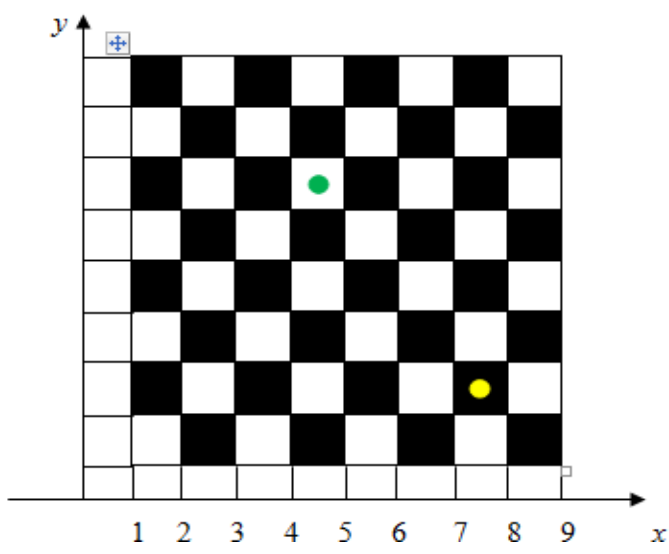

Gambar 1. Soal nomor 1 pada prototype awal sebelum divalidasi

Denah berikut menunjukkan tempat duduk siswa di kelas.

\begin{tabular}{|c|c|c|c|c|c|}
\hline Sofi & Mita & Anisa & Citra & Rezky & Alif \\
\hline Iskandar & Ana & Anggara & Hana & Ruby & Randa \\
\hline Salsa & Habibi & Ainun & Daffa & Gita & Nabila \\
\hline Alfi & Ubay & Najib & Faiq & Jihan & Dany \\
\hline Zafran & Rifan & Azza & Selfi & Ridwan & Jirayut \\
\hline Mahrus & Adil & Windy & Indana & Robit & Andika \\
\hline
\end{tabular}

Guru

Andika duduk di pojok kanan kelasnya, ia ingin berpindah tempat duduk yang ditempati oleh Mita. Dari denah tempat duduk tersebut, berapakah perpindahan yang dilakukan oleh Andika dari tempat duduknya menuju tempat duduk Mita? Jelaskan jawaban kalian!

Gambar 2. Soal nomor 2 pada prototype awal sebelum divalidasi 
Liga Catur Utama Jerman (Bundesliga) merupakan salah satu kompetisi antar klub catur terkuat di dunia. Sebanyak 16 tim bermain di delapan papan menggunakan sistem setengah kompetisi. Pada salah satu pertandingan klub catur Baden Baden (kuning) melawan klub Schwäbisch Hall (merah). Dengan menggunakan aturan catur, tunjukkan langkah-langkah pergeseran yang dapat disusun oleh klub Baden Baden dengan bishop (menteri) untuk menyingkirkan pion (prajurit) milik klub Schwäbisch Hall menggunakan konsep translasi dan disajikan dalam bentuk matriks jika penomoran dan penamaan papan catur dianggap kordinat kartesius dengan $(1, \mathrm{H})$ $=(1,1)$ !

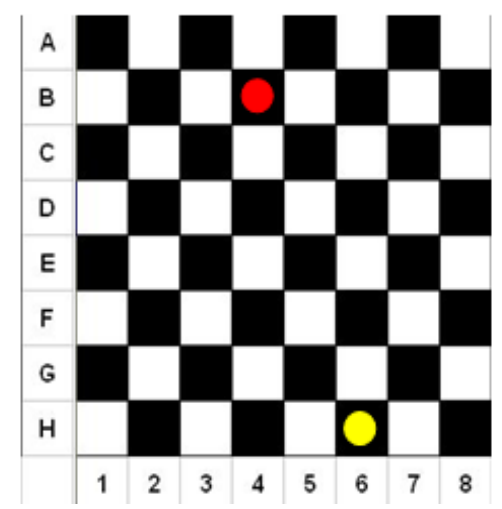

Gambar 3. Soal nomor 3 pada prototype awal sebelum divalidasi 
Batik pisang Lumajangmerupakansalah satu produkterbaik yang ada di Lumajang dan menjadi kebangganKabupaten Lumajang. Cirikhas dari batik ini adalah motifmotifnya berdasar pisang yang berbeda dengan batik dari daerah lain. Cara pembuatan batik ini salah satunya dengan metode cap. Jika pada satu cap dapat menghasilkan 4 gambar pisang dan 4 gambar daum, maka pada ukurankain $100 \mathrm{cmx}$ $40 \mathrm{~cm}$ berapakah banyak gambar pisang dan daun? Sajikan dalam bentuk matriks konsep translasi.

$$
20 \mathrm{~cm}
$$

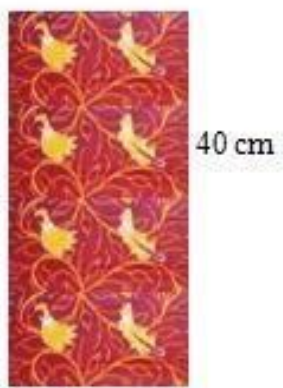

\section{$100 \mathrm{~cm}$}

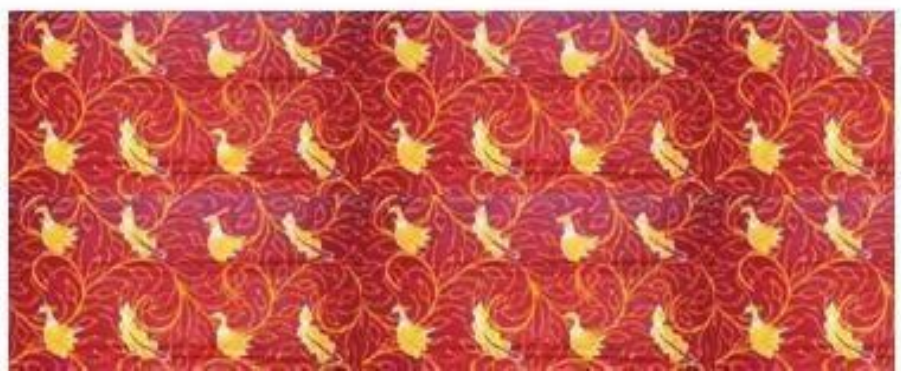

$40 \mathrm{~cm}$

Gambar 4. Soal nomor 4 pada prototype awal sebelumdivalidasi

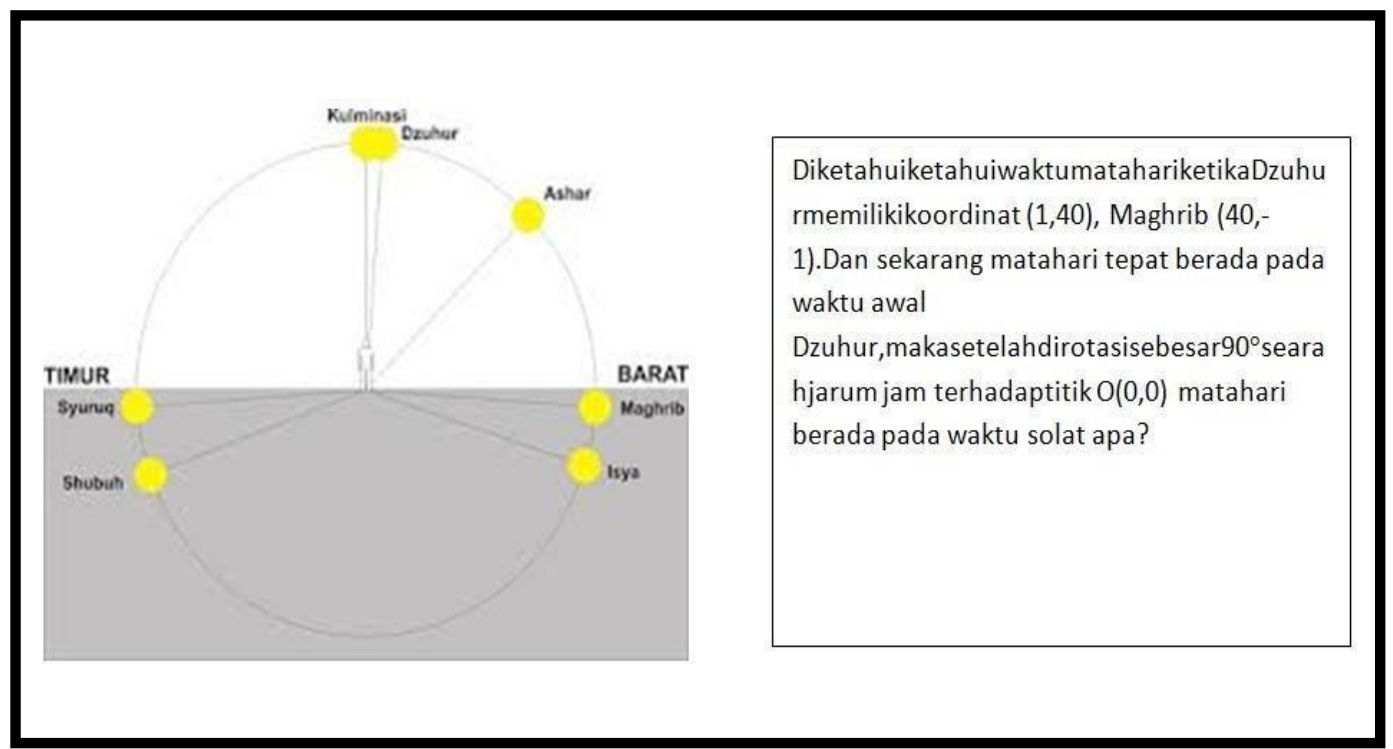

Gambar 5. Soal nomor 5 pada prototype awal sebelumdivalidasi 

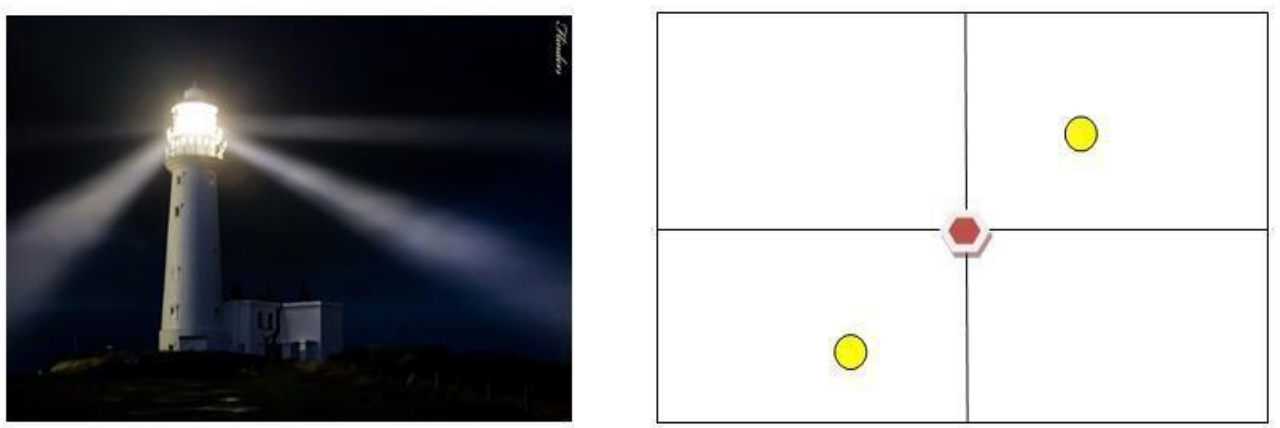

Merah :mercusuar $(0,0)$

kuning : sorotlampu $(7,8)$ dan $(-7 .-8)$

sorotlampumercusuarberotasisebesar $10^{\circ}$ per 2 detik.

Tentukankoordinatsorotlampusetelah 12 detik!

Gambar 6. Soal nomor 6 pada prototype awal sebelumdivalidasi

1. Misalkan $A B C D$ adalah meja bilyar, dengan $A(5,3), B(-5,3), C(-5,-3), D(5,-3)$. Jika bola yang berada di $\mathrm{P}(-3,-1)$ dipukul hingga melaju mengenai bola $\mathrm{R}(3,-1)$ dengan ketentuan jika bola harus mengenai sisi $C D$ sebelum mengenai bola di $R$, maka koordinat titik sasaran $Q$ pada sisi meja bilyar adalah...

Gambar 7. Soal nomor 7 pada prototype awal sebelumdivalidasi

2. Diketahui dua buah rumah dengan letak masing-masing di $A(8,2)$ dan $B(4,5)$. Sebuah tiang listrik akan dipasang sepanjang jalan pada sumbu Y. agar kawat yang digunakan untuk menghubungkan rumah $\mathrm{A}$ dan $\mathrm{B}$ adalah minimum, maka letak tiang listrik adalah...

Gambar 8. Soal nomor 8 pada prototype awal sebelumdivalidasi

\section{Tahap formative evaluation}

\section{Self Evaluation}

ARITMATIKA, Vol. 2, No. 1, Juni 2021 
Hal yang dilakukan pada tahap ini adalah pada perangkat soal yang telah dibuat dievaluasi sendiri oleh peneliti. Dalam hal ini penulis mendapat bantuan dari beberapa orang teman sejawat yang telah berpengalaman dalam pengembangan soal-soal PISA. Hasil dari self evaluation ini disebut prototype.

\section{Expert Reviews}

Langkah selanjutnya yang dilakukan terhadap prototype hasil dari self evaluation adalah prototyping. Tahap ini dilakukan dengan expert review. Tahap expert reviews merupakan pengujian validitas butir soal oleh pakar (expert). Hal ini dilakukan dengan cara mencermati dan menilai setiap butir soal berdasarkan konten, konstruk, dan bahasa. Konten yang dinilai adalah kesesuaian dengan kurikulum yang digunakan dan materi yang dipelajari siswa kelas XI SMA KD 3.5 tentang Menganalisis dan membandingkan transformasi dan komposisi transformasi dengan menggunakan matriks dan KD 4.5 Menyelesaikan masalah yang berkaitan dengan matriks transformasi geometri (translasi, refleksi, dilatasi, dan rotasi). Konstruk yang dicermati adalah kesesuaian dengan karakteristik soal PISA. Validasi bahasa yang dimaksud adalah kesesuaian penggunaan bahasa pada butir soal dengan kaidah bahasa yang berlaku (EYD).

Tahap ini melibatkan dosen ahli sebagai validator, yaitu dosen Tadris Matematika IAIN Jember, Bapak Dimas Danar Septiadi, M. Pd,. Berdasarkan pencermatan validator, diperoleh kesimpulan bahwa soal matematika model PISA pada Materi Transformasi Geometri Kelas XI SMA telah memenuhi indikator valid dari segi konten, konstruk, dan bahasa. Berikut tabel rekapan lembar validasi dari tahap expert reviews.

Tabel 1. Rekapan lembar validasi dari soal nomor 1, 2, 3, 4, 5, 6, 7, dan 8 .

\begin{tabular}{|c|c|c|c|c|c|c|}
\hline \multirow[b]{2}{*}{ No } & \multirow[b]{2}{*}{$\begin{array}{c}\text { Aspek } \\
\text { Validasi }\end{array}$} & \multirow[b]{2}{*}{ Aspek yang Dinilai } & \multicolumn{4}{|c|}{ Skor Penilaian } \\
\hline & & & $\begin{array}{c}1 \\
\text { dan } \\
2\end{array}$ & $\begin{array}{c}3 \\
\text { dan } \\
4\end{array}$ & $\begin{array}{c}5 \\
\text { dan } \\
6\end{array}$ & $\begin{array}{c}7 \\
\text { dan } \\
8\end{array}$ \\
\hline \multirow{3}{*}{1 . } & \multirow{2}{*}{ Validasi Isi } & $\begin{array}{l}\text { a. Soal sesuai dengan } \\
\text { indikator soal tes }\end{array}$ & 3 & 4 & 3 & 2 \\
\hline & & $\begin{array}{lr}\text { b. Soal yang disajikan dapat } \\
\text { menggali } & \text { pemecahan } \\
\text { masalah } & \text { berdasarkan }\end{array}$ & 3 & 4 & 3 & 2 \\
\hline & & indikator soal PISA & & & & \\
\hline \multirow[b]{2}{*}{2.} & \multirow[b]{2}{*}{$\begin{array}{c}\text { Validasi } \\
\text { Konstruksi }\end{array}$} & $\begin{array}{l}\text { a. Soal yang disajikan } \\
\text { merupakan soal uraian }\end{array}$ & 4 & 4 & 4 & 4 \\
\hline & & $\begin{array}{l}\text { b. Soal yang disajikan } \\
\text { merupakan soal Matematika } \\
\text { materi Transformasi } \\
\text { Geometri } \\
\text { tipe PISA }\end{array}$ & 3 & 4 & 3 & 2 \\
\hline
\end{tabular}


3. Validasi

Bahasa a. Bahasa yang digunakan pada

soal sesuai dengan kaidah

Bahasa Indonesia yang baik dan benar

b. Pertanyaan soal tidak menimbulkan penafsiran ganda (ambigu)

c. Pertanyaan soal komunikatif (menggunakan bahasa yang sederhana dan mudah dipahami)

iran

Validasi Petunjuk a. Petunjuk pengerjaan soal jelas

b. Petunjuk pengerjaan soal tidak menimbulkan penafsiran ganda

3

3

3

3

3

$\begin{array}{llll}3 & 3 & 3 & 3 \\ 2 & 3 & 3 & 2\end{array}$

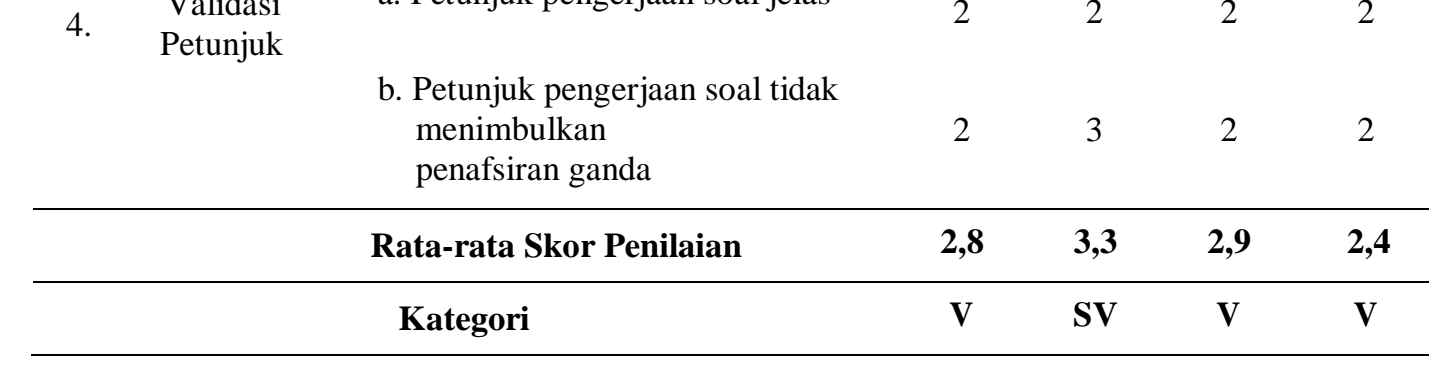

\section{Expert Reviews}

Langkah selanjutnya yang dilakukan terhadap prototype hasil dari self evaluation adalah prototyping. Tahap ini dilakukan dengan expert review. Tahap expert reviews merupakan pengujian validitas butir soal oleh pakar (expert). Hal ini dilakukan dengan cara mencermati dan menilai setiap butir soal berdasarkan konten, konstruk, dan bahasa. Konten yang dinilai adalah kesesuaian dengan kurikulum yang digunakan dan materi yang dipelajari siswa kelas XI SMA KD 3.5 tentang Menganalisis dan membandingkan transformasi dan komposisi transformasi dengan menggunakan matriks dan KD 4.5 Menyelesaikan masalah yang berkaitan dengan matriks transformasi geometri (translasi, refleksi, dilatasi, dan rotasi). Konstruk yang dicermati adalah kesesuaian dengan karakteristik soal PISA. Validasi bahasa yang dimaksud adalah kesesuaian penggunaan bahasa pada butir soal dengan kaidah bahasa yang berlaku (EYD).

Tahap ini melibatkan dosen ahli sebagai validator, yaitu dosen Tadris Matematika IAIN Jember, Bapak Dimas Danar Septiadi, M. Pd,. Berdasarkan pencermatan validator, diperoleh kesimpulan bahwa soal matematika model PISA pada Materi Transformasi Geometri Kelas XI SMA telah memenuhi indikator valid dari segi konten, konstruk, dan bahasa. Berikut tabel rekapan lembar validasi dari tahap expert reviews.

Tabel 1. Rekapan lembar validasi dari soal nomor 1, 2, 3, 4, 5, 6, 7, dan 8 .

Keterangan:

$0-1=$ Tidak Valid dan ganti (TV)

$1,1-2=$ Cukup Valid dan revisi $(\mathrm{CV})$

ARITMATIKA, Vol. 2, No. 1, Juni 2021 
$2,1-3$ = Valid dan revisi $(\mathrm{V})$

$3,1-4=$ Sangat Valid dan revisi (SV)

Dari hasil validasi oleh validator, pada soal nomor satu validator meminta untuk membuat soal kembali. Hal ini dikarenakan adanya konsep soal tentang translasi yang sama dengan soal yang lainnya dan menyarankan membuat soal yang berbeda akan tetapi dalam bentuk konsep yang sama. Pada soal nomor dua, validator meminta untuk memperbaiki penggunaan kata dalam soal dan merevisi soal kembali, dan juga menyarankan untuk menambahkan pertanyaan pada soal tersebut dikarenakan jawabannya terlalu mudah terbaca jika dilihat pada soal.

Pada soal nomor tiga, validator menyarankan untuk mengganti nama klub dengan nama yang lebih mudah untuk dibaca dan familiar didengar. Pada soal nomor empat, validator menyarankan untuk mengganti gambar dengan yang lebih jelas dan menunjukkan gambar cap batik serta menghapus keterangan ukuran cap batik pada soal.

Untuk soal nomor lima, validator menyarankan mengganti soal karena bahasa kurang prediktif, menimbulkan penafsiran ganda, dan jawaban terlalu mudah terbaca, validator juga menyarankan soal dengan materi dilatasi, namun peneliti tidak hanya menuliskan soal tentang dilatasi, tapi juga menambahkan soal tentang translasi. Untuk soal nomor enam, validator meminta untuk menghapus keterangan yang tertera pada soal lalu langsung mencantumkannya pada gambar.

Pada soal nomor tujuh dan delapan, validator menyarankan untuk mengganti soal secara total karena soal tersebut bukan termasuk karakteristik soal PISA dan tidak mencantumkan gambar yang berisi informasi.

Saran dan komentar yang disampaikan oleh validator dijadikan sebagai masukan ntuk revisi prototype. Temuan yang diperoleh pada tahap expert reviews juga digunakan dalam merevisi prototype. Berikut adalah hasil prototyping setelah soal divalidasi oleh ahli dapat dilihat pada Gambar 9, 10, 11, 12, $13,14,15,16$. 
Amati dan tentukan penyelesaian soal-soal berikut ini !

1. Perhatikan lintasan pada sirkuit dibawah ini

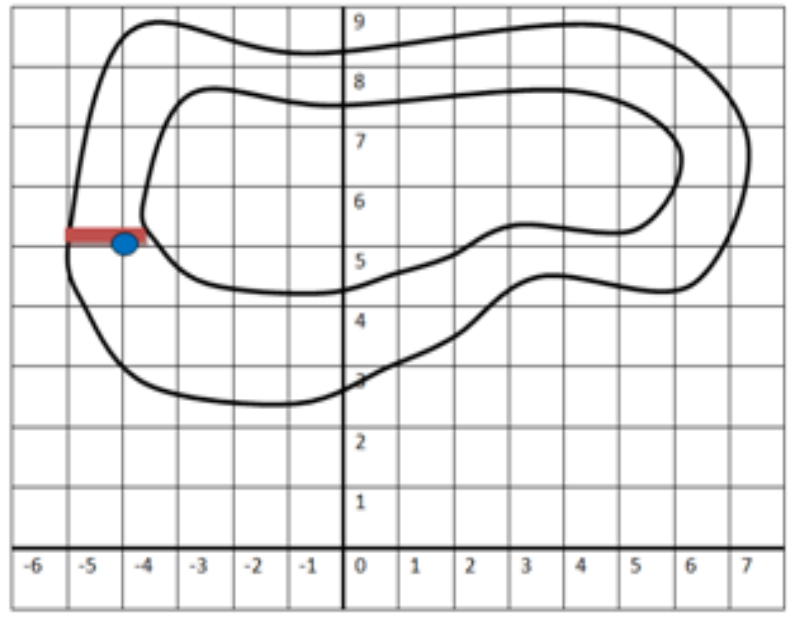

Kejuaraan Dunia MotoGP atau kerap disebut sebagai MotoGP saja atau nama resminya FIM MotoGP World Championship adalah kelas utama dari seri balapan Grand Prix Sepeda Motor. Dulunya kelas ini dikenal dengan nama kelas $500 \mathrm{cc}$ atau biasa disebut GP500 yang pertama kali digelar sejak musim 1949. Salah satu pembalap yang terkenal pada ajang tersebut bernama Valentino Rossi, pada suatu hari ia sedang berlatih disebuah sirkuit balap dengan lintasan berbelok-belok. Dia melaju kencang yang dimulai dari garis start pada koordinat $(-4,5)$, Tentukan salah satu kemungkinan perpindahan paling sedikit yang dilakukan pembalap tersebut setelah 5 kali putaran!

Gambar 9. Soal nomor 1 hasil prototyping setelah divalidasi 
2. Denah berikut menunjukkan tempat duduk siswa di kelas.

\begin{tabular}{|l|l|l|l|l|l|}
\hline Sofi & Mita & Anisa & Citra & Rezky & Alif \\
\hline Iskandar & Ana & Anggara & Hana & Ruby & Randa \\
\hline Salsa & Habjbi & Ainun & Daffa & Gita & Nabila \\
\hline Alfi & Ubay & Najib & Faiq & Jihan & Dany \\
\hline Zafran & Rifan & Azza & Selfi & Ridwan & Jirayut \\
\hline Mahrus & Adil & Windy & Indana & Robit & Andika \\
\hline & \multicolumn{7}{|l}{} \\
\hline
\end{tabular}

Andika duduk di pojok kanan kelasnya tepat koodinat $(6,1)$, ia ingin berpindah tempat duduk yang ditempati oleh Mita. Dari denah tempat duduk tersebut,

a. Ada berapakah konsep perpindahan yang bisa diterapkan?

b. Perpindahan tersebut bisa mengggunakan konsep apa? Jelaskan!

Gambar 10. Soal nomor 2 hasil prototyping setelah divalidasi

Amatilah soal berikut ini lalu tentukan penyelesaiannya!

1. Liga Catur Utama Jerman (Bundesliga) merupakan salah satu kompetisi antar klub catur terkuat di dunia. Sebanyak 16 tim bermain di delapan papan menggunakan sistem setengah kompetisi. Pada salah satu pertandingan klub catur kuning melawan klub merah. Dengan menggunakan aturan catur, tunjukkan langkahlangkah pergeseran yang dapat disusun oleh klub kuning dengan bishop (menteri) untuk menyingkirkan pion (prajurit) milik klub merah menggunakan konsep translasi dan disajikan dalam bentuk matriks jika penomoran dan penamaan papan catur dianggap kordinat kartesius dengan $(1, \mathrm{H})=(1,1)$ !

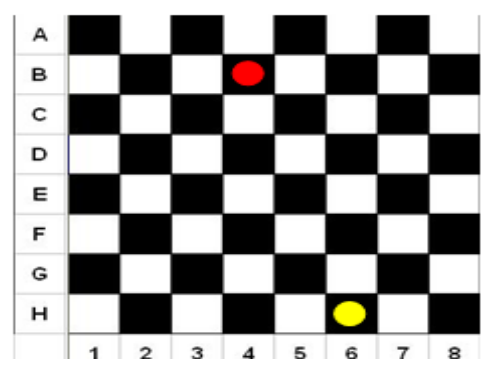

Gambar 11. Soal nomor 3 hasil prototyping setelah divalidasi 
2. Batik pisang Lumajang merupakan salah satu produk terbaik yang ada di Lumajang dan menjadi kebanggan Kabupaten Lumajang. Ciri khas dari batik ini adalah motif dasar yang bergambar piasng dan berbada dengan batik dari daerah lain. Cara. pembuatan batik ini aslah satunya dengan metode cap. Tentukan berapaksh banyak gambar pisang dan daun piaang pada ukuran kain $100 \mathrm{~cm} \times 40 \mathrm{~cm}$ ? Sajikan dalam bentuk matriks konsep translasi.

Alat cap batik
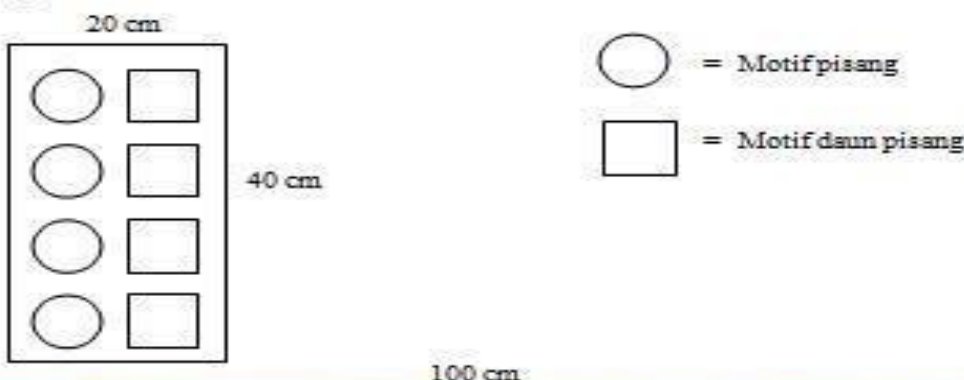

$100 \mathrm{~cm}$

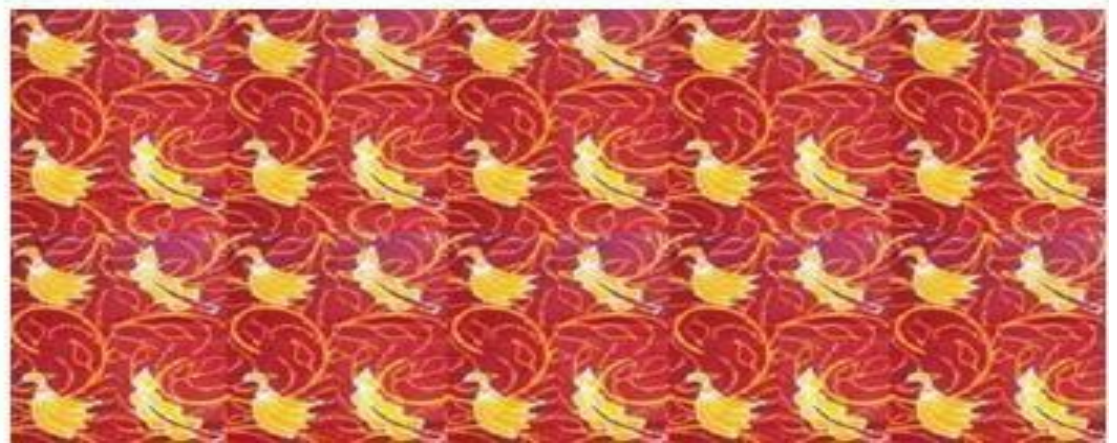

Gambar 12. Soal nomor 4 hasil prototyping setelah divalidasi 
Amatisoal dengan baik kemudian tentukan penyelesaiannya!

1.

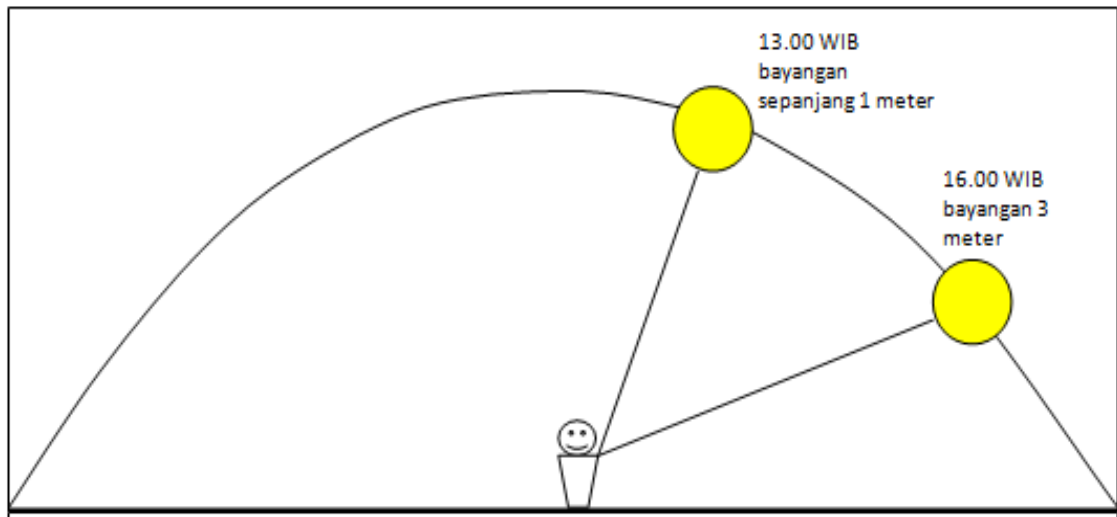

Adi memiliki tinggi $180 \mathrm{~cm}$. gambar diatas menunjukkan panjang bayangan ketika tinggi matahari mencapaititik tertentu.

Tentukan :

a. Panjang bayangan Adi ketika pukul 17.00 WIB !

b. Matriks pergeseran ujung bayangan Adi dari jam 13.00 WIB sampai 17.00 WIB jika ujung bayangan Adi pada jam 13.00 berada pada koordinat $(33,0)$ dengan skala $1: 1$ !

Gambar 13. Soal nomor 5 hasil prototyping setelah divalidasi
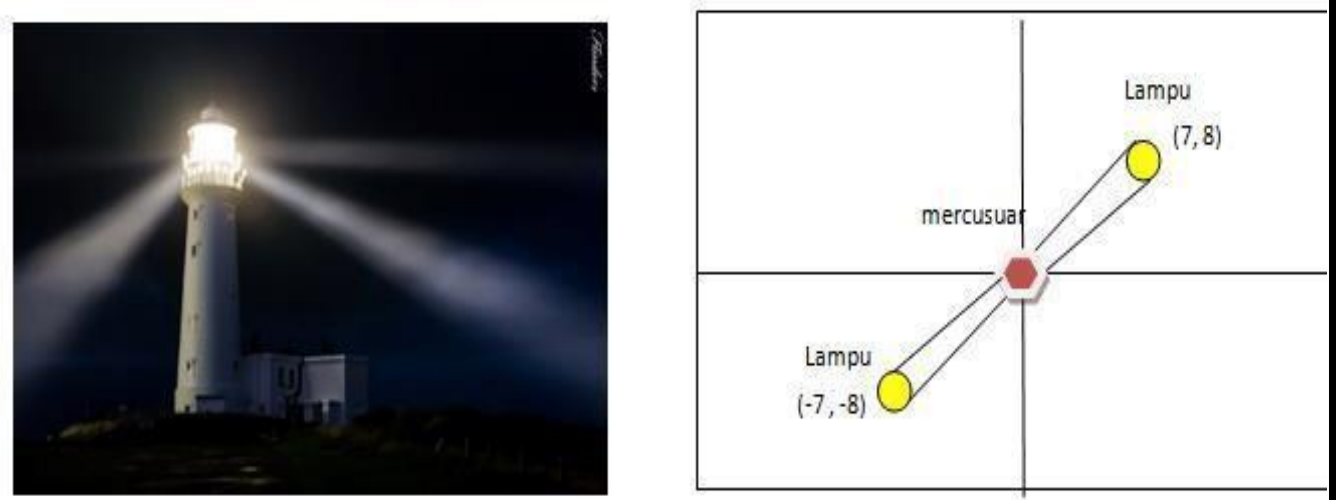

Sorot lampu mercusuar berotasi sebesar $10^{\circ}$ per 2 detik.

Tentukan koordinat sorot lampu setelah 12 detik!

Gambar 14. Soal nomor 6 hasil prototyping setelah divalidasi 
Amati soal berikut dan tentukan penyelesaiannya!

1.

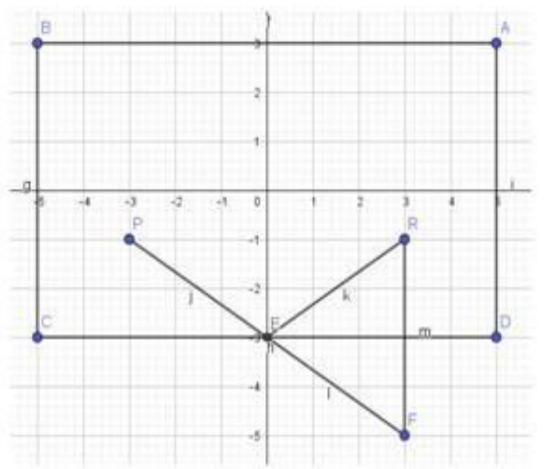

Misalkan ABCD adalah sebuah meja bilayar. $\mathrm{P}$ dan $\mathrm{R}$ adalah bola, bola $\mathrm{P}$ akan dipukul hingga mengenai bola R. dari ilustrasi diatas jawablah pertanyaan berikut :

a. Ada berapa transformasigeometriyang dapat digunakan

b. Jika bola yang berada di $\mathrm{P}(-3,-1)$ dipukul hingga melaju mengenai bola $\mathrm{R}(3,-1)$ dengan ketentuan jika bola harus mengenai sisi $C D$ sebelum mengenai bola di $R$, maka koordinat titik sasaran E pada sisi meja bilyar adalah

Gambar 15. Soal nomor 7 hasil prototyping setelahdivalidasi

2.

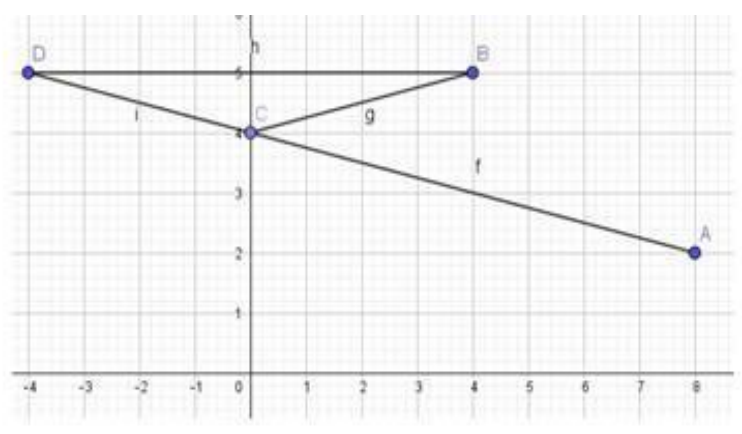

Beberapa pekerja tiang listrik akan memasang tiang listrik di sepanjang jalan pada sumbu Y. Tiang listrik tersebut akan dipasang disetiap dua rumah yang akan dihubungkan. Pada gambar ada dua buah rumah dengan letak masing-masing di A dan B. dari ilustrasi tersebut jawablah pertanyaan berikut:

a. Transformasigeometriapayang dapat digunakan dalam masalah ini

b. Dimanakah letak tiang listrik agar kawat yang digunakan untuk menghubungkan rumah A dan B adalah minimum

Gambar 16. Soal nomor 8 hasil prototyping setelah divalidasi 
Penelitian ini menghasilkan soal matematika model PISA materi Transformasi Geometri kelas XI SMA yang telah dikembangkan berdasarkan langkah-langkah yang disusun sesuai dengan kerangka kerja (framework) PISA dan diadaptasikan dengan kurikulum K13 revisi. Berdasarkan hasil deskripsi dari tahap persiapan dan uji validitas dari ahli menunjukkan soal-soal yang dikembangkan sudah sesuai dengan kerangka kerja (framework) PISA, meliputi isi atau konten matematika; proses yang perlu dilakukan peserta didik ketika mengamati suatu gejala, menghubungkan gejala itu dengan matematika, kemudian memecahkan masalah yang diamatinya.

\section{SIMPULAN DAN SARAN}

Berdasarkan hasil penelitian dan pembahasan disimpulkan bahwa 8 butir soal matematika model PISA pada materi transformasi geometri kelas XI SMA yang dikembangkan telah valid dan memiliki efek potensial. Kevalidan soal diperoleh dari proses validasi pada tahap expert reviews. Pada tahap expert reviews, pakar menilai dari segi konten, konstruk, dan bahasa. keseluruhan soal valid dengan rincian nilai validitas 2.8 untuk soal nomor 1 dan 2 , nilai 3.3 untuk soal nomor 3 dan 4, nilai 2.9 untuk soal nomor 5 dan 6, serta nilai 2.4 untuk soal nomor 7 dan 8 . Karakteristik yang dibangun dalam pengembangan soal ini adalah perangkat soal yang dikembangkan memiliki ciri soal PISA pada materi transformasi geometri dan memiliki efek potensial. Efek potensial dalam hal ini adalah memunculkan pelibatan kemampuan dasar matematis yang beragam pada proses penyelesaiannya.

Berdasarkan hasil penelitian dan kesimpulan disarankan hendaknya dapat menggunakan perangkat soal matematika model pada materi transformasi geometri kelas XI SMA yang telah dikembangkan ini sesuai dengan materi ajar untuk melatih kemampuan literasi matematis siswa atau sebagai alternatif dalam memperkaya variasi soal matematika yang diberikan kepada siswa.

\section{DAFTAR PUSTAKA}

\section{Books:}

Kohar, A. W. (2014). Pengembangan soal matematika model PISA: sebuah alternatif langkah awal memperbaiki prestasi literasi matematika siswa Indonesia.

National Council of Teacher Mathematics. (2000). Principles and Standards for Schools Mathematics. Reston. VA: NCTM 
Sugiyono. (2007). Metode Penilaian Pendidikan (Pendekatan Kuantitatif, Kualitatif dan R/D). Bandung: Alfabeta.

Widjaja, W. 2013. The Used of Contextual Problems Support Mathematical Learning.

\section{Online journal:}

Abdul Halim Fathani. (2016). Pengembangan Literasi Matematika Sekolah dalam Perspektif Multiple Intelligences. EduSains. Vol. 4, No. 2.

Anisah; Zulkardi; Darmawijoyo. Pengembangan Soal Matematika Model PISA pada Konten Quantity untuk Mengukur Kemampuan Penalaran Matematis Siswa Sekolah Menengah Pertama. Jurnal Pendidikan Matematika Universitas Negeri Sriwijaya. Vol. 5, No. 1.

Charmila, Ninik ; Zulkardi; Darmawijoyo. (2016). Pengembangan Soal Matematika Model Pisa Menggunakan Konteks Jambi. Jurnal Penelitian dan Evaluasi Pendidikan. Vol 20, No 2 .

Johar, Rahmah. (2012). Domain Soal PISA untuk Literasi matematika. Jurnal Peluang. Vol. 1, No. 1

Kurniati, Dian; Romi Harimukti; Nur Asiyah Jamil. (2016). Kemampuan Berpikir Tingkat Tinggi Siswa SMP di Kabupaten Jember dalam Menyelesaikan Soal Berstandar PISA. Jurnal Elemen. Vol. 2, No. 1.

Pulungan, Delyanti Azzumarito. (2014). Pengembangan Instrumen Tes Literasi Matematika Model PISA. Journal of Educational Research and Evaluation. Vol. 3, No. 2.

Putra, Yudi Yunika ; Zulkardi ; Yusuf Hartono. (2016). Pengembangan Soal Matematika Model PISA Konten Bilangan untuk Mengetahui Kemampuan Literasi Matematika Siswa. Jurnal Elemen. Vol. 2, No. 1

Journal on Mathematics Education, Vol. 4, No. 2.

\section{Theses, Dissertation:}

Kadir, K., \& Masi, L. (2013). Penggunaan konteks dalam pembelajaran matematika untuk meningkatkan keterampilan sosial siswa SMP. Dalam Prosiding KNPM V Malang.

Wardani, A. K. (2014). Pengembangan Soal Matematika Model PISA untuk Program Pengayaan Kelas VII SMP. Dalam Prosiding SEA-DR Kedua.

Zulkardi, Z. (2002). Developing a learning on realistic mathematics education for Indonesian students teachers. Doctoral dissertation. Enschede: University of Twente, Enschede. The Nederland. 